\title{
Health Care Provider
}

National Cancer Institute

\section{Source}

National Cancer Institute. Health Care Provider. NCI Thesaurus. Code C16666.

Persons who provides health care as part of their job responsibilities: or a person or organization who is licensed to supply health care. 